\title{
Behaviour of cement composites with ceramic fibres exposed to higher temperatures
}

\author{
M. Čáchová, D. Koňáková, E. Vejmelkokvá, J. Kot'átková \\ \& R. Černý \\ Department of Materials Engineering and Chemistry, \\ Faculty of Civil Engineering, Czech Technical University in Prague, \\ Czech Republic
}

\begin{abstract}
This study is aimed at the evaluation of the behaviour of Portland cement based composites reinforced by ceramic fibres when exposed to higher temperatures. The main emphasis is given on the determination of influence of ceramic fibres, which are added in order to improve the post-heating maintenance of mechanical properties of studied composites. Ceramic fibres are, thanks to its origin, predestined to have good resistance to fire and high temperatures. Their influence is investigated through the way of experimental measurement performed on three mixtures varying in the amount of used fibres. Also reference composites without reinforcement are tested. Two sets of each material are made and exposed to different temperature conditions. Loading temperatures are set as $105^{\circ} \mathrm{C}$ and $400^{\circ} \mathrm{C}$ and studied properties are basic physical properties, mechanical parameters, liquid transport properties and diffusion characteristics. Results generally prove the beneficial effects of ceramic fibres on the mechanical properties and on the overall behaviour of the composites for both prior and post heating state.
\end{abstract}

Keywords: concrete, ceramic fibres, basic physical properties, mechanical parameters, hydric transport characteristics.

\section{Introduction}

The development of cement composites is nowadays one of the main concerns in the field of building materials research. As ordinary concrete has already met its limits, new ways how to improve the properties of cement based materials are 
being sought, such as development of high performance concrete or special composites based on Portland cement. Due to the unfavourable low tensile strength of cement-based materials and brittleness, the addition of various types of fibres found its importance and many investigators [1-9] concern themselves with finding the proper design and studying the properties of fibre-reinforced composites. There has been many types of fibres investigated so far, showing certain problems with each single type. For example, steel fibres, which show otherwise many positive properties, unfortunately tends to agglomerate during manufacture, which causes mixing problems and special techniques are thus required for obtaining a product of good quality. Glass fibres show very poor stability in the high alkaline environment of cement paste and so only modified glass with high corrosion resistance can be used. Asbestos fibres which used to be utilised in cement composites very often in the past, were found to have serious adverse health effects. Carbon fibres have very good mechanical properties, but their wide use is limited by their high cost.

The ceramic fibres seem to be a promising material, which has good mechanical properties, is stable in the alkaline cement paste, is economically feasible and easy to handle. Its manufacture subsists in melting of raw materials, namely kaolin, quartz and alumina, at about $2000^{\circ} \mathrm{C}$ in an arc furnace and then centrifuging or blowing. Thanks to their composition, consisting mainly of $\mathrm{Al}_{2} \mathrm{O}_{3}$ and $\mathrm{SiO}_{2}$, their resistance to alkalis is much higher in comparison to glass fibres. The good durability properties of ceramic fibres were proved by several researchers [1-3]. To name a few, Low and Beaudoin [1] reinforced cement composites by wollastonite fibres, Sugama et al. [2] investigated calcium aluminate/fly ash/polyphosphate cements with ceramic fibre reinforcement and Yon et al. [3] introduced new type of calcia/alumina fibres, which are produced by the process of inviscid melt spinning. Sugama et al. [2] also showed superior properties of fibre reinforced composites when exposed to hydrothermal conditions.

As ceramic fibres go through high temperatures during their manufacture, they are predestined to improve the composite behaviour under the exposition to heat. This paper studies the basic physical properties, mechanical parameters, liquid water transport and water vapour transport characteristics of ceramic fibres reinforced Portland cement based composites and the composites' behaviour when after loaded by heat to temperatures of $400^{\circ} \mathrm{C}$.

\section{Material}

The composition of studied composites is presented in Table 1. Ordinary Portland cement CEM I 52.5 was used as the binder. This cement originates from Lafarge, a.s. Č́źžkovice. Silica aggregate was used in four size fractions in calculated relative proportions for good granulometry. Small water/cement ratio was designed in order to gain very compact microstructure and so, the plasticizer SIKA1035 was added in order to reach specified consistency of the fresh mixture. Four sets of samples differed in the amount of used ceramic fibres. The reference 
set PKR was made without any fibres, and sets PKK1, PKK2 and PKK3 contained 10,20 and $30 \mathrm{~kg} \mathrm{~m}^{-3}$ of ceramic fibres respectively.

Table 1: The composition of studied composites.

\begin{tabular}{|l|c|c|c|c|}
\hline \multicolumn{1}{|c|}{ Component } & PKR & PKK1 & PKK2 & PKK3 \\
\hline Portland cement CEM 52.5 & 900 & 900 & 900 & 900 \\
\hline Silicate Aggregates 0.1/0.6 & 275 & 275 & 275 & 275 \\
\hline Silicate Aggregates 0.3/0.8 & 55 & 55 & 55 & 55 \\
\hline Silicate Aggregates 0.6/1.2 & 165 & 165 & 165 & 165 \\
\hline Silicate Aggregates 1.0/4.0 & 605 & 605 & 605 & 605 \\
\hline Ceramic fibres & - & 10 & 20 & 30 \\
\hline Plasticizer SIKA1035 & 13.5 & 13.5 & 13.5 & 13.5 \\
\hline Water & 225 & 225 & 225 & 225 \\
\hline
\end{tabular}

\section{Experimental methods}

All measured properties were assessed for all sets of samples in two states: after drying at $105^{\circ} \mathrm{C}$, which was set as a reference state and after the exposition to heat - specifically to temperature of $400^{\circ} \mathrm{C}$. Temperature loading was performed in special electric top-cover furnace and heating rate was set as $0.5^{\circ} \mathrm{C}$ per min. After reaching temperature of $400^{\circ} \mathrm{C}$, samples were exposed to that temperature for 3 hours. Cooling was spontaneous and also took place in the furnace.

\subsection{Basic physical properties}

For characterization of basic physical properties water vacuum saturation method [10] was used. Using this method bulk density, matrix density and open porosity of each sample were determined. Firstly, all specimens were dried in an oven at temperature $105^{\circ} \mathrm{C}$ until the free and part of physically bound water escaped, and then they were weighed. Afterward they were placed in a desiccator, filled with de-aired water and then there was vacuum created by a vacuum pump. At these conditions the samples were kept at least 24 hours for full saturation. Saturated samples were weighed on air and under water. From the recorded data, the precise volume was calculated using the Archimede's law. Knowing the precise volume, weight of dry and saturated sample and its Archimede's weight, the open porosity, bulk density and matrix density were calculated.

\subsection{Mechanical parameters}

Compressive strength and tensile strength were determined to characterize the mechanical parameters of studied samples. The bending strength was determined with the use of the procedure described in CSN EN 12390-5 [11], with the loading rate of $0.04 \mathrm{MPa} / \mathrm{s}$ on prismatic samples of dimensions $40 \times 40 \times 160 \mathrm{~mm}$. On the left fragments of samples, which left after bending strength test, the compressive strength was measured. The performance was done according to the standard ČSN 
EN 12390-3 [12]. The constant loading rate was $0.2 \mathrm{MPa} / \mathrm{s}$. Both experiments were performed standardly after 28 days from casting of the samples.

\subsection{Transport of water vapour}

Water vapour transport properties were measured with the use of wet-cup and dry cup-methods described in the standard ČSN 727031 [13]. Firstly, all samples were insulated on lateral sides in order to ensure the one-directional transport of water vapour through the sample. Then the samples were placed into cups filled with silica gel or water for dry-cup and wet-cup method respectively and sealed by a sealing material to exclude any possible movement of water vapour past the sample. Cups were placed in a climatic chamber with set conditions of $50 \%$ relative humidity and $25^{\circ} \mathrm{C}$. The filling inside the cup created an environment of $5 \% \mathrm{RH}$ and $97 \% \mathrm{RH}$ for dry-cup and wet-cup respectively. These differences of conditions inside and outside the cup created pressure gradients, which was the driving force for water vapour movement through the sample. During four weeks the samples were periodically weighed to assess the mass loss/gain until reaching the steady state. From the recorded data the water vapour diffusion coefficient and water vapour diffusion resistance factor were calculated.

\subsection{Transport of liquid water}

The absorption experiment was used to assess the water absorption coefficient for characterization of liquid water transport properties [14]. All samples were firstly insulated on all lateral sides for transport of water through the sample in only one direction and immersed 1-2 mm deep under the water level. The increase in weight was recorded by an automatic balance in predefined steps, which were small enough to gain authentic dependence of weight gain on the square root of time. From the output data the water absorption coefficient was determined as the slope of the regression line.

\section{Experimental results}

\subsection{Basic physical properties}

Values of basic physical properties obtained from water vacuum saturation method are presented in Tables 2 and 3 for reference state and after exposition to $400^{\circ} \mathrm{C}$ respectively. Variations of bulk density between the single sets of samples are within $2 \%$, variations of matrix density within $1 \%$ and $3 \%$ respectively. The highest bulk density was found for samples PKK1 and the lowest for PKK3 for both states of conditioning, and very similarly in the case of matrix density. The differences in bulk density between the reference state and state after heating were negligible - within $1 \%$. However, for matrix density the differences between the two states were higher. The most marked difference was found for set of reference samples PKR as the value for samples after heating was by $3 \%$ higher compared to the reference state. As the amount of ceramic fibres rose, the difference was decreasing, reaching a difference lower than $1 \%$ for PKK3. 
The open porosity was found as the most varying basic physical property depending on reinforcement level. The open porosity in the reference state rose with increasing amount of fibres, as for PKK3 the open porosity was by $17 \%$ higher than in the case of PKR. However, after heating the open porosity was the highest for the reference set PKR (by 23\% higher compared to reference state), while the lowest values were found for samples PKK1. The open porosity further rose with rising amount of fibres, but the differences between the two states decreased. It can be thus said that in the means of open porosity, samples PKK2 and PKK3 after the exposition to $400^{\circ} \mathrm{C}$ behaved almost the same as in the reference state; the growth of open porosity was by about $5 \%$.

Table 2: $\quad$ Basic physical properties of the studied materials at $105^{\circ} \mathrm{C}$.

\begin{tabular}{|c|c|c|c|}
\hline & $\begin{array}{c}\text { Bulk density } \\
{\left[\mathrm{kg} \mathrm{m}^{-3}\right]}\end{array}$ & $\begin{array}{c}\text { Matrix density } \\
{\left[\mathrm{kg} \mathrm{m}^{-3}\right]}\end{array}$ & $\begin{array}{c}\text { Open porosity } \\
{[\%]}\end{array}$ \\
\hline PKR & 2174 & 2402 & 9.5 \\
\hline PKK1 & 2201 & 2439 & 9.7 \\
\hline PKK2 & 2163 & 2425 & 10.8 \\
\hline PKK3 & 2141 & 2415 & 11.4 \\
\hline
\end{tabular}

Table 3: $\quad$ Basic physical properties of the studied composites at $400^{\circ} \mathrm{C}$.

\begin{tabular}{|c|c|c|c|}
\hline & $\begin{array}{c}\text { Bulk density } \\
{\left[\mathrm{kg} \mathrm{m}^{-3}\right]}\end{array}$ & $\begin{array}{c}\text { Matrix density } \\
{\left[\mathrm{kg} \mathrm{m}^{-3}\right]}\end{array}$ & $\begin{array}{c}\text { Open porosity } \\
{[\%]}\end{array}$ \\
\hline PKR & 2158 & 2465 & 12.4 \\
\hline PKK1 & 2202 & 2468 & 10.8 \\
\hline PKK2 & 2157 & 2433 & 11.4 \\
\hline PKK3 & 2111 & 2400 & 12.0 \\
\hline
\end{tabular}

\subsection{Mechanical properties}

The values of mechanical properties are summarized in Tables 4 and 5. In Table 4 there are values of bending strengths and compressive strengths at reference state. The best values of compressive strength were found for set of samples PKK2, followed by PKK1, PKR and lastly PKK3. The total difference between the highest and lowest value was by about $6 \%$. Values of bending strength showed the same trend, only the difference between PKK2 and PKK3 was higher - by $10 \%$. Also the trends for both studied properties after the exposition to $400^{\circ} \mathrm{C}$ (Table 5) were the same, however the values were significantly lower than in the reference state. The decrease in compressive strength after heating was for PKR, PKK1, PKK2 and PKK3 respectively by 53\%, 51\%, 48\% and 57\%. Therefore, it is visible that in the means of compressive strength the best performance was found for the set of samples PKK2. The decrease of bending strength was by $20 \%, 16 \%, 14 \%$ and $17 \%$ for PKR, PKK1, PKK2 and PKK3 respectively. It implies that also in the case of bending strength the mixture PKK2 showed the best behaviour, although the drop in values was significantly lower than in the case of compressive strength. 
68 High Performance and Optimum Design of Structures and Materials II

Table 4: $\quad$ Mechanical properties of studied plasters at $105^{\circ} \mathrm{C}$.

\begin{tabular}{|c|c|c|}
\hline & $\begin{array}{c}\text { Compressive strength } \\
{[\mathrm{MPa}]}\end{array}$ & $\begin{array}{c}\text { Bending strength } \\
{[\mathrm{MPa}]}\end{array}$ \\
\hline PKR & 93.2 & 17.5 \\
\hline PKK1 & 95.1 & 17.9 \\
\hline PKK2 & 96.5 & 18.6 \\
\hline PKK3 & 90.6 & 16.8 \\
\hline
\end{tabular}

Table 5: $\quad$ Mechanical properties of studied plasters at $400^{\circ} \mathrm{C}$.

\begin{tabular}{|c|c|c|}
\hline & $\begin{array}{c}\text { Bending strength } \\
{[\mathrm{MPa}]}\end{array}$ & $\begin{array}{c}\text { Compressive strength } \\
{[\mathrm{MPa}]}\end{array}$ \\
\hline PKR & 43.6 & 16.3 \\
\hline PKK1 & 46.6 & 14.6 \\
\hline PKK2 & 50.2 & 16.2 \\
\hline PKK3 & 39.1 & 13.6 \\
\hline
\end{tabular}

\subsection{Transport of water vapour}

Tables 6 and 7 present the obtained values of water vapour transport properties. Water vapour diffusion coefficient for the reference state of samples rose with increasing amount of fibres. The difference between the lowest value (for PKR) and the highest value (for PKK3) was by $13 \%$ and $11 \%$ for dry-cup and wet-cup respectively. For samples after the exposition to $400^{\circ} \mathrm{C}$ the similar trend, as in the case of open porosity, can be found for both wet-cup and dry-cup methods. The highest water vapour diffusion coefficient was found for the reference material PKR and the lowest for samples PKK1. The differences between values of reference state and state after heating were decreasing with the rising amount of fibres. The highest increase of values was found for reference material PKR by $22 \%$ for dry-cup and by $14 \%$ for wet-cup method. The values of water vapour diffusion resistance showed the same trends as in the case of water vapour diffusion coefficient, only inversely, as expected.

Table 6: $\quad$ Transport of water vapour of studied materials at $105^{\circ} \mathrm{C}$.

\begin{tabular}{|c|c|c|c|c|}
\hline \multirow{2}{*}{} & \multicolumn{2}{|c|}{$\begin{array}{c}\text { Water vapour diffusion } \\
\text { coefficient }\left[\mathrm{m}^{2} \mathrm{~s}^{-1}\right]\end{array}$} & \multicolumn{2}{c|}{$\begin{array}{c}\text { Water vapour diffusion } \\
\text { resistance factor [-] }\end{array}$} \\
\cline { 2 - 5 } & Dry cup & Wet cup & Dry cup & Wet cup \\
\hline PKR & $1.57 \mathrm{E}-7$ & $2.02 \mathrm{E}-7$ & 145.9 & 114.0 \\
\hline PKK1 & $1.70 \mathrm{E}-7$ & $2.15 \mathrm{E}-7$ & 135.2 & 107.0 \\
\hline PKK2 & $1.74 \mathrm{E}-7$ & $2.29 \mathrm{E}-7$ & 132.7 & 104.1 \\
\hline PKK3 & $1.80 \mathrm{E}-7$ & $2.27 \mathrm{E}-7$ & 127.8 & 101.7 \\
\hline
\end{tabular}


Table 7: $\quad$ Transport of water vapour of studied materials at $400^{\circ} \mathrm{C}$.

\begin{tabular}{|c|c|c|c|c|}
\hline \multirow{2}{*}{} & \multicolumn{2}{|c|}{$\begin{array}{c}\text { Water vapour diffusion } \\
\text { coefficient }\left[\mathrm{m}^{2} \mathrm{~s}^{-1}\right]\end{array}$} & \multicolumn{2}{c|}{$\begin{array}{c}\text { Water vapour diffusion } \\
\text { resistance factor [-] }\end{array}$} \\
\cline { 2 - 5 } & Dry cup & Wet cup & Dry cup & Wet cup \\
\hline PKR & $2.01 \mathrm{E}-7$ & $2.36 \mathrm{E}-7$ & 114.3 & 97.6 \\
\hline PKK1 & $1.72 \mathrm{E}-7$ & $2.06 \mathrm{E}-7$ & 133.7 & 111.6 \\
\hline PKK2 & $1.86 \mathrm{E}-7$ & $2.25 \mathrm{E}-7$ & 123.9 & 102.5 \\
\hline PKK3 & $1.93 \mathrm{E}-7$ & $2.28 \mathrm{E}-7$ & 119.1 & 100.8 \\
\hline
\end{tabular}

\subsection{Transport of liquid water}

Values of water absorption coefficient obtained from absorption experiment are given in Table 8 . The values grew with increasing amount of ceramic fibres in the reference state. The differences between the lowest value for reference material PKR of samples and the highest value of PKK3 was by $40 \%$, which means a moderate worsening of the liquid water transport properties of studied composites. On the other hand after exposition to $400^{\circ} \mathrm{C}$ the reference samples PKR increased in values of water absorption coefficient significantly - by $42 \%$, while PKK1, PKK2 and PKK3 only by $16 \%, 7 \%$ and $5 \%$ respectively. The total lowest value after heating was found to be for samples PKK1.

Table 8: Transport of liquid water of studied composites.

\begin{tabular}{|c|c|c|}
\hline \multirow{2}{*}{} & \multicolumn{2}{|c|}{ Water absorption coefficient $\left[\mathrm{kg} \mathrm{m}^{-2} \mathrm{~s}^{-1 / 2}\right]$} \\
\cline { 2 - 3 } & $105^{\circ} \mathrm{C}$ & $400^{\circ} \mathrm{C}$ \\
\hline PKR & 0.0075 & 0.0128 \\
\hline PKK1 & 0.0102 & 0.0112 \\
\hline PKK2 & 0.0111 & 0.0119 \\
\hline PKK3 & 0.0125 & 0.0131 \\
\hline
\end{tabular}

\section{Conclusion}

The paper was aimed at evaluation of selected properties of Portland cement composites incorporating ceramic fibres. Mainly the influence of varying amount of ceramic fibres was studied through the view of experimental program. Four mixtures composed of $0,10,20$ or $30 \mathrm{~kg} \mathrm{~m}^{-3}$ of ceramic fibres, were manufactured and tested in reference state (dried at $105^{\circ} \mathrm{C}$ ) and after heating to $400{ }^{\circ} \mathrm{C}$. Results can be summarized as follows:

- Bulk density differed only slightly between the single sets of samples (within 3\%) and was negligibly influenced by heating (by less than 1\%). Variations of matrix density were in the reference state also small (within $2 \%$ ), but after heating the values increased, the highest increase was found for reference set of samples - by $3 \%$. 
- Open porosity rose significantly with the increasing amount of ceramic fibres for the reference state. But by heating the open porosity of reference samples rose significantly, while in the other cases the increase was not so remarkable. The lowest values of open porosity after heating were found for set of samples with $10 \mathrm{~kg} \mathrm{~m}^{-3}$ of ceramic fibres.

- The values of mechanical properties did not precisely follow the trend of open porosity. The highest values of compressive and bending strength were found for set of samples with $20 \mathrm{~kg} \mathrm{~m}^{-3}$ of fibres. Heating had significant effect on the loss of compressive strength, which ranged from $48 \%$ up to $57 \%$. Less significant but still high deterioration was found in bending strengths due to the temperature heating. Values decreased from $14 \%$ to $20 \%$. The lowest fall was found in the case of material containing $20 \mathrm{~kg} \mathrm{~m}^{-3}$ of ceramic fibres.

- Water vapour diffusion coefficient rose with increasing amount of ceramic fibres for samples in reference state in both wet-cup and dry-cup methods. After heating the highest values were found for the reference samples and the lowest for material containing $10 \mathrm{~kg} \mathrm{~m}^{-3}$ of ceramic fibres.

- The ability to transport liquid water was found to be higher with higher amount of ceramic fibres. However, after the exposition to $400^{\circ} \mathrm{C}$ the values of reference samples rose very distinctively, while the sets with fibres behaved better. The total lowest values of absorption coefficient after temperature exposure was found for material with $10 \mathrm{~kg} \mathrm{~m}^{-3}$.

Due to the origin of ceramic fibres they have good resistance to high temperatures which is beneficial for composites when exposed to heat. Next to this, its good stability in the alkaline environment of cement paste, quite low cost and good mechanical properties makes ceramic fibres to be a good alternative of fibre reinforcement in cement-based materials to other types of fibres. With respect to all presented characteristic as well as the economic aspects the best ratio of ceramic fibres amount was found to be $20 \mathrm{~kg} \mathrm{~m}^{-3}$ in mixture.

\section{Acknowledgement}

This research has been supported in the Czech Republic under project SGS16/199/OHK1/3T/11.

\section{References}

[1] Low, N. M. P., Beaudoin, J. J., Flexural Strength and Microstructure of Cement Binders Reinforced with Wollastonite Micro-fibers, Cement and Concrete Research, 23(4), pp. 905-916, 1993.

[2] Sugama, T., Weber, L., Brothers, L. E., Ceramic fibre-reinforced calcium aluminate/fly ash/polyphosphate cements at a hydrothermal temperature of $280^{\circ} \mathrm{C}$, Advances in Cement Research, 14(1), pp. 25-34, 2002. 
[3] Yon, K., Mitchell, B. S., Dunn, S. A., Koutsky, J. A., Introduction of new reinforcement for cementitious materials-Calcia/alumina (CA) fibers formed by the inviscid melt-spinning (IMS) process, Cement and Concrete Composites 15(3), pp. 165-172, 1993.

[4] Lau, A., Anson, M., Effect of High Temperatures on High Performance Steel Fibre Reinforced Concrete. Cement and Concrete Research, 36(9), pp. 1698-1707, 2006.

[5] Jogl, M., Reiterman, P., Holčapek, O., Kotátková, J., Effects of High Temperature Treatment on the Mechanical Properties of Basalt Fiber Reinforced Aluminous Composites. Applied Mechanics and Materials, 732, pp. 111-114, 2015.

[6] Wang, Z. L., Wu, J., Wang, J. G., Experimental and Numerical Analysis on Effect of Fibre Aspect Ratio on Mechanical Properties of SRFC. Construction and Building Materials, 24(4), pp. 559-565, 2010.

[7] Jiang, C., Fan, K., Wu, F., Chen, D., Experimental Study on the Mechanical Properties and Microstructure of Chopped Basalt Fibre Reinforced Concrete. Materials \& Design, 58, pp. 187-193, 2014.

[8] Kalifa, P., Chéné, G., Gallé, C., High-Temperature Behaviour of HPC with Polypropylene Fibres: From Spalling to Microstructure. Cement and Concrete Research, 31(10), pp. 1487-1499, 2001.

[9] Mohammadi, Y., Singh, S. P., Kaushik, S. K., Properties of Steel Fibrous Concrete Containing Mixed Fibres in Fresh and Hardened State. Construction and Building Materials, 22(5), pp. 956-965, 2008.

[10] Roels, S., Carmeliet, J., Hens, H., Adan, O., Brocken, H., Černý, R., Pavlík, Z., Hall, C., Kumaran, K., Pel, L., Plagge, R., Interlaboratory Comparison of Hygric Properties of Porous Building Materials. Journal of Thermal Envelope and Building Science, 27(4), pp. 307-325, 2004.

[11] ČSN EN 12390-5: Testing of Hardened Concrete - Part5: Flexural Strength. 2009.

[12] CSN EN 12390-3: Testing of Hardened Concrete - Part 3: Compressive Strength, 2002.

[13] ČSN 72 7031: Determination of water vapour diffusion coefficient of building materials by method without temperature gradient, Czech Standards Institution, 2001.

[14] Kumaran, M.K., Moisture Diffusivity of Building Materials from Water Absorption Measurements. Journal of Building Physics, 22, pp. 349-355, 1999. 